\title{
Ethical issues in kidney transplantation - reflections from Nigeria
}

This article was published in the following Dove Press journal:

Transplant Research and Risk Management

18 November 2010

Number of times this article has been viewed

\author{
Joseph Olusesan Fadare' \\ Babatunde L Salako² \\ 'Department of Medicine, Kogi \\ State Specialist Hospital, Lokoja; \\ ${ }^{2}$ Department of Medicine, University \\ of Ibadan, Ibadan, Nigeria
}

\begin{abstract}
Organ transplantation has become a life-saving procedure for many disease conditions hitherto considered incurable. Kidney transplantation, now the treatment of choice for end-stage renal disease, is the commonest solid organ transplantation carried out in the world at the moment and it is the only solid organ transplantation done in Nigeria. This procedure, in addition to prolonging lives, also provides better quality of life and is evaluated as cost-effective, because it makes more resources available to other sectors of the economy. Organ transplantation in general and kidney transplantation in particular are fraught with ethical issues and dilemmas worldwide. Some of the ethical issues arising in the setting of developing countries like Nigeria may differ from those in countries where this procedure is established. Informed consent of the donor and the recipient is a major requirement for both organ donation and transplantation. Regarding donation, the ethical issues may differ depending on the type of organ donation, ie, whether it is living-related, living-unrelated, cadaveric, or from brain-dead individuals. Commodification of organs is identified as an ethical dilemma, and arguments for and against this practice are put forward here. Confidentiality of donor information, fairness and equity in donor selection, and access to kidney transplantation when needed are also discussed. Finally, the issue of safety of organ harvesting for the donor and of the transplantation process itself, and the possible long-term consequences for both parties are investigated.
\end{abstract}

Keywords: kidney transplantation, ethical issues, developing countries, Nigeria

\section{Introduction}

Organ transplantation has become a life-saving procedure for many disease conditions hitherto considered incurable. This procedure, in addition to prolonging lives, also enables better quality of life and is considered to be cost-effective because it makes more resources available for other sectors of the economy. Kidney transplantation, which has now become the treatment of choice for end-stage renal disease, is the commonest solid organ transplantation being carried out in the world at the moment and, in developing countries like Nigeria and Pakistan, it is the only solid organ transplantation that is practiced. In the US alone, over 93,000 renal transplants were carried out between 1988 and 1996. ${ }^{1}$ Although there is a paucity of accurate data regarding this practice in developing countries, evidence from the literature indicates that there has been a considerable boom in organ transplantation, especially of kidneys. ${ }^{2}$ In Nigeria, it could be said that this procedure is still in its infancy, with just over a hundred kidney transplants carried out to date in a limited number of centers, and the number of kidney transplants done abroad ("imported kidneys") cannot be ascertained. Organ transplantation in general, and kidney transplants in particular,
Correspondence: Joseph O Fadare Department of Internal Medicine, Kogi State Specialist Hospital, Lokoja, Nigeria Tel +2348I38048I27

Email jofadare@gmail.com 
are fraught with ethical issues and dilemmas worldwide, about which there is ongoing debate, especially because of the shortage of organs in developed countries with established transplant programs. In the Nigerian context, some of these ethical issues might not be relevant at the moment because of the "embryonic" stage of its transplantation program. Although a few studies have investigated attitudes to, knowledge about, and the practice of organ donation and transplantation in Nigeria, little has been mentioned about the ethical issues associated with the procedure. ${ }^{3,4}$ The purpose of this paper is to highlight these ethical issues and dilemmas, especially as they relate to the practice of kidney transplantation in a developing country where the procedure is still in its infancy. It is expected that this paper will highlight some differences in current ethical issues from those ongoing in developed countries with extensive experience in the practice of kidney transplantation.

\section{Ethical issues}

Because the process of organ transplantation involves removing an organ from one person (donor) and transferring it to another (recipient), the need to obtain informed consent from both persons (or their surrogate decision-makers) is compulsory. This is in keeping with the ethical principle of respect for persons and is expressed in many ethical guidelines today. To start the discussion about consent, it is important to mention the many sources of organs for transplantation, ie, living donor (related and nonrelated), cadaveric donor, and brain-dead patients. In countries where transplantation is well established, organs are sourced from both living and cadaveric donors using different strategies, ie, an opt-in (explicit consent), opt-out (presumed consent), donation after brain death, donation after controlled cardiac death, and extended criteria for deceased donors. ${ }^{5}$ The presumed consent strategy is now being applied in many developed countries as a way of increasing the availability of organs, but the results have thus far fallen short of expectations. ${ }^{6}$ The ethical issue associated with presumed consent is that by making people opt out of organ donation, do we respect their rights as individuals to selfdetermine? Are these people who are unwilling to donate organs going to be put under societal pressure or made to feel guilty about their decision to opt out? Proponents of the opt-out strategy, however, would argue that the end justifies the means, in that many more lives will be saved using this strategy, and this outweighs any violation of the rights of donors. This strategy of opting out has not been adopted in developing countries, probably due to the absence or gross underdevelopment of organ transplantation programs for socioeconomic and cultural reasons in these countries. ${ }^{7}$ The living donor strategy remains the main source of organs in developing countries, and informed consent is nonnegotiable. The ethical dilemma differs when considering related and nonrelated living organ donation. With the former, the dilemma is whether the decision to donate an organ is totally free of coercion from family members. This is especially important in the extended family setting prevalent in many African countries where the pressure (direct or subtle) could be enormous. Let us consider the case of $\mathrm{Mr} \mathrm{X}$ who has end-stage kidney disease and needs a kidney transplant. $\mathrm{He}$ has been told by his nephrologists that his best bet will be to obtain a kidney from one of his family members. and he mentions this to his son every time he visits and begs him to save his life. Although this is a hypothetical scenario, it is played out in reality many times. In this scenario, how voluntary can a decision by the son to donate a kidney to his father be? Can we say that the decision is absolutely free of coercion, either subtle or explicit? Is there not a risk of the donor overlooking the risks to himself/herself because of the feeling of responsibility towards a loved one, and can we confidently say that the main motive for donation is altruistic? In the African setting, where the family is central to decision-making, the risk of coercion is even greater, and here the autonomy of the donor is totally eroded. For living nonrelated donors, the main motive for organ donation in many developing countries has been found to be financial.

The nonheart-beating donor strategy is based on the "dead donor" rule which states that "vital organs should be procured from persons only after they are determined as dead". ${ }^{8}$ Although this strategy is not being practiced in Nigeria or in most developing countries at the moment, it is expected to become an important source of organs when the practice of organ transplantation becomes established in these countries. This rule confirms the commitment of society to respect human life and the fact that persons are not used as a means to an end, but as an end in itself. At the moment, brain death ${ }^{9}$ and cardiopulmonary ${ }^{10}$ criteria are used to define death, although the moment or process of death is difficult to pinpoint. Another point that comes to mind is the assumption that these death criteria have been put in place to facilitate availability of organs for transplant, and that because of this, physicians would do little to resuscitate patients in cardiac arrest. ${ }^{11}$ This argument has brought to the fore the need for widely accepted criteria for death and a protocol for organ recovery. The issues relating to the integrity and wholeness of the human body are also ethical 
problems that need to be mentioned. ${ }^{12}$ Some cultures still abhor any form of mutilation of the living or dead body for any purpose at all, even though most religions now approve of cadaver organ donation on the basis of brotherly love, doing good, and sustaining life. ${ }^{13,14}$

\section{Commodification of organs}

The sale and trafficking of organs, especially in developing countries, has emerged as the major problem confronting the practice of organ transplantation worldwide. ${ }^{15}$ Although there is a worldwide consensus that no payment should be made for organs from either living donors or deceased individuals, the shortage and scarcity of organs for transplantation and the associated long waiting period has led to what is termed "transplantation commercialism" in developing countries where regulation of transplantation practices is inadequate. ${ }^{16}$ The ethical issues here are linked to the question of "body ownership", and there seems to be no consensus on this issue. ${ }^{17}$ Some would argue that, based on the principle of autonomy and respect for persons, people may donate their organs for altruistic reasons as well as for financial gain. This, according to them, will greatly increase the availability of organs for transplantation. However, while this argument might be plausible, it is known that payment for organs can influence the decision to donate, and more people from the low socioeconomic classes would be enticed into doing this, leading to inequities in donation both within a country and internationally. There is also a danger of vital medical information being withheld by potential donors, which may lead to the transplanted organ carrying some unknown disease that could compromise the outcome of transplantation or the overall health of the recipient. Some workers have advocated a form of "compensated donation", whereby donors will have some sort of reimbursement for lost time and assistance with health insurance, ${ }^{5}$ but this does not eliminate completely the risk of abuse. Indeed, the Iranian model of paid and regulated living-unrelated kidney donation $^{7}$ is an example of the workability of this approach, although as mentioned earlier, it does not remove all the ethical dilemmas. The Declaration of Istanbul on Transplant Tourism and Organ Trafficking also supports such schemes that remove economic disincentives as a way of encouraging altruistic living organ donation.

\section{Confidentiality}

Confidentiality of information given to physicians by patients has always been a basic component of the ethics of the medical profession, and organ transplantation is no exception. In this case, the most important information is the result of screening and compatibility tests which could affect the outcome of the procedure. However, circumstances whereby the health of third parties could be affected by these results are rare exceptions to the confidentiality rule, and even in these situations, the donors involved should be informed before the information is disclosed to the affected parties.

\section{Fairness and equity}

Fairness and equity in organ procurement needs to be viewed in terms of commodification of organs and of equitable access of the populace to organ transplantation, when indicated. In procuring organs for transplantation, efforts should be made to ensure a fair selection of donors, using explicit criteria, and without any form of discrimination. To address the question of equitable access to organ transplantation in this age of shortage of organs, several rationing strategies have been put in place in transplantation programs in many developed countries, and these strategies are also laden with ethical dilemmas. ${ }^{18}$ For example, if a donor kidney is available for transplantation, and two recipients, a 45-year-old teacher and a 70-yearold man, have good histocompatibility matching with the kidney, who gets the kidney? It is likely that most people would choose the younger patient, based on reasons of future productivity and better utility for the community, and most protocols for transplantation actually exclude patients older than 65 years, but recent studies have shown good results in transplanted patients over this age. ${ }^{19}$ So do we have any right to value the life of one person more than another based on years already lived? Let us take a look at another scenario of a patient with end-stage renal disease secondary to human immunodeficiency virus (HIV)-associated nephropathy and another with diabetic nephropathy being considered for the same donated kidney. By what criteria do we choose to whom to give the kidney? Can we be accurate in estimating the longevity of the transplanted kidney in both potential recipients? Now that HIV/acquired immune deficiency syndrome (AIDS) has become a potentially chronic treatable (albeit not curable) disease like diabetes, how do we proceed in this case? There are no ready answers to these questions, but raising them enables us to understand the complexity of the issues being discussed. With the increasing prevalence of HIV/AIDS and hepatitis B infection in many Sub-Saharan countries, the main ethical issue that will arise in the near future will be that of discrimination regarding access to organs. 
Perhaps the most important problem limiting access to kidney transplantation in Nigeria is the cost of the procedure. The average cost of the procedure in Nigeria is in the range of 6-10 million Naira (US\$ 40,000-70,000), without considering the financial implications of postoperative immunosuppressants, and this in a country where more than $70 \%$ of the population live on below two US dollars daily. ${ }^{20}$ The situation is made even more difficult by the lack of centralized health insurance, hence payment for health care is mainly "out of pocket" in these countries..$^{21,22}$ This is an contrast with developed countries where there is usually some form of health insurance to relieve the financial burden on patients. One dilemma that is peculiar to developing countries like Nigeria is the problem of continued access to maintenance immunosuppressant drugs post-transplantation. Our experience is that many patients find it very difficult to find the resources to sustain these medications because of their high cost, hence risking late rejection of the graft. We believe that a mechanism needs to be put in place by the World Health Organization and other international agencies to help resolve this problem, as was done in the case of antiretroviral drugs.

\section{Quality assurance and safety}

Two of the core principles of biomedical ethics are beneficence and nonmaleficence, and both are relevant when discussing organ transplantation. While beneficence (to do good) is the main principle behind organ donation and transplantation, nonmaleficence (to do no harm) is also relevant. While the aim of transplanting a "normal" kidney is to improve the health status and prolong the life of the recipient, it is important to ensure that the process of organ recovery is as safe as possible, and that both the living donor and recipient are followed up to detect and manage any short- or longterm sequelae..$^{23}$ The competence of the medical/surgical team responsible for the transplant process should also be of the highest order, so as to ensure outcomes comparable with those in developed countries. It is very necessary to ensure that the economic aspects of the procedure do not in any way compromise accepted worldwide standards. The informed consent process should ensure that all necessary information regarding the potential risks of the procedure, the possibility of graft rejection, and adverse effects of the immunosuppressant used by the recipient are made available to the potential donor and recipient.

\section{Conclusion}

Ethical issues in kidney transplantation, especially in the context of a developing country with relatively little experience, may differ in certain areas. Many of the ethical dilemmas are related to informed consent by the living donor, commodification of the kidney, quality assurance, and safety of the procedure. There is also a need to ensure fairness and equity in access to the procedure, as well as to post-transplant immunosuppressive agents.

\section{Disclosure}

The authors report no conflicts of interest in this work.

\section{References}

1. Hariharan S, Johnson CP, Bresnahan BA, Taranto SE, McIntosh MJ, Stablein D. Improved graft survival after renal transplantation in the United States, 1988 to 1996. N Engl J Med. 2000;342:605-612.

2. Muthusethupathi MA, Rajendran S, Jayakumar M, Vijayakumar R. Evaluation and selection of living related kidney donors - our experience in a government hospital. J Assoc Physicians India. 1998;46: $526-529$.

3. Agaba EI, Ocheke IE, Agaba PA, et al. Willingness of Nigerian healthcare workers to donate kidneys. Int J Artif Organs. 2008;31:329-332.

4. Odusanya OO, Ladipo CO. Organ donation: Knowledge, attitudes, and practice in Lagos, Nigeria. Artif Organs. 2006;30:626-629.

5. Voo TC, Campbell AV, de Castro LD. The ethics of organ transplantation: Shortages and strategies. Ann Acad Med Singapore. 2009;38: 359-356.

6. Rithalia A, McDaid C, Suekarran S, Norman G, Myers L, Sowden A. A systematic review of presumed consent systems for deceased organ donation. Health Technol Assess. 2009;13:1-95.

7. Ghods AJ, Savaj S. Iranian model of paid and regulated living-unrelated kidney donation. Clin J Am Soc Nephrol. 2006;1:1136-1145.

8. Arnold RM, Youngner SJ. The dead donor rule: Should we stretch it, bend it, or abandon it? Kennedy Inst Ethics J. 1993;3:263-278.

9. President's Commission for the Study of Ethical Problems in Medicine and Biomedical and Behavioral Research. Defining Death: A report on the medical, legal, and ethical issues in the determination of death. Washington, DC: The Commission; 1981.

10. Shemie SD, Baker AJ, Knoll G, et al. National recommendations for donation after cardiocirculatory death in Canada: Donation after cardiocirculatory death in Canada. Can Med Assoc J. 2006;175:S1.

11. Kerridge IH, Saul P, Lowe M, McPhee J, Williams D. Death, dying and donation: Organ transplantation and the diagnosis of death. $J$ Med Ethics. 2002;28:89-94.

12. Rothman DJ, Rose E, Awaya T, Cohen B, Daar A, Dzemeshkevich SL. The Bellagio Task Force report on transplantation, bodily integrity, and the international traffic in organs. Transplant Proc. 1997;29: 2739-2745.

13. Golmakani MM, Niknam MH, Hedayat KM. Transplantation ethics from the Islamic point of view. Med Sci Monit. 2005;11:105-109.

14. Bruzzone P. Religious aspects of organ transplantation. Transplant Proc. 2008;40:1064-1067.

15. Steering Committee of the Istanbul Summit. Organ trafficking and transplant tourism and commercialism: The Declaration of Istanbul. Lancet. 2008;372:5-6.

16. Barsoum RS. Trends in unrelated-donor kidney transplantation in the developing world. Pediatr Nephrol. 2008;23:1925-1929.

17. Björkman B, Hansson SO. Bodily rights and property rights. $J$ Med Ethics. 2006;32:209-214.

18. Courtney AE, Maxwell AP. The challenge of doing what is right in renal transplantation: Balancing equity and utility. Nephron Clin Pract. 2009;111:62-67.

19. Fabrizii V, Winkelmayer WC, Klauser R, et al. Patient and graft survival in older kidney transplant recipients: Does age matter? $J \mathrm{Am}$ Soc Nephrol. 2004;15:1052-1060. 
20. World Development Report 2010. World Bank. Available from: www. worldbank.org/wdr2010. Accessed Sep 222010.

21. Garg CC, Karan AK. Reducing out-of-pocket expenditures to reduce poverty: A disaggregated analysis at rural-urban and state level in India. Health Policy Plan. 2009;24:116-128.
22. Leive A, Xu K. Coping with out-of-pocket health payments: Empirical evidence from 15 African countries. Bull World Health Organ. 2008; 86:849-856

23. Salmela K. Quality and safety of organ transplantation. Ann Transplant. 2004;9:51-52.

\section{Publish your work in this journal}

Transplant Research and Risk Management is an international, peerreviewed open access journal focusing on all aspects of transplantation and risk management to achieve optimal outcomes in the recipient improving survival and quality of life. The journal welcomes submitted papers covering original research, basic science, clinical studies, reviews \& evaluations, guidelines, expert opinion and commentary, case reports and extended reports. The manuscript management system is completely online and includes a very quick and fair peer-review system, which is all easy to use. Visit http://www.dovepress.com/ testimonials.php to read real quotes from published authors.

Submit your manuscript here: http://www.dovepress.com/transplant-research-and-risk-management-journal 